\title{
A STUDY TO ASSESS THE BARRIERS AND FACILITATORS OF BLOOD DONATION AMONG UNIVERSITY STUDENTS OF SOUTH INDIA
}

\author{
Abhishek Chaturvedi 1,7, Anup Kumar2,8, Bhaskar Tiwary3*, Pallabi Roy 4,7, Lochan Khullar4,7, \\ Anitha Guru5, Piyusha Majumdar6
}

\author{
1: Department of Biochemistry, Melaka Manipal Medical College (Manipal campus), Manipal Academy of Higher Education, \\ Manipal-576104, Karnataka, India \\ 2: International Institute of PopulationSciences, Mumbai-40088, Maharashtra, India \\ 3: Concurrent Measurement and Learning Unit, Bihar Technical Support Program, CARE India, Bihar, India \\ 4: Manipal College of Dental Sciences, Manipal, Manipal Academy of Higher Education, Manipal-576104, Karnataka, India. \\ 5: Manip al Centre for European Studies (MCES), Manipal A ca demy of Higher Education, Manipal-576104, Karnataka, India \\ 6: SD Gupta School of Public Health, IIHMR University, Jaipur-302029, Rajasthan, India \\ 7: Volunteer Services Organization (VSO), Manipal A cademy of Higher Education, Manipal-576104, Karnataka, India \\ 8: Asian Development Research Institute, Patna-800013, Bihar, India
}

Correspondence:tiwaryb97@gmail.com

\section{ABSTRACT}

\section{INTRODUCTION}

Donated blood is very crucial and lifesaving for those who require large volumes of blood in any medical emergency. Many blood donation camps are routinely organized to fill this void of demand and supply. In a university campus associated with a hospital, it is important that student volunteers should contribute towards the increase in demand for blood during times of crisis. This makes it imperative to understand their perception of this noble cause. METHODS

A descriptive cross-sectional study was conducted among 354 volunteers of a university campus using convenience sampling. The primary outcome was to assess the factors that influence voluntary blood donation among the volunteers. The adjusted association was performed using logistic regression. R Console was used for statistical analysis. Odds ratios and $p$-value $<0.05$ with $95 \%$ confidence intervals were calculated to determine the level of significance. RESULTS

A total of 354 responses were received and analysed. Among these, 38.98\%, ( $n=138)$ participants had donated blood at least once. Factors that were significantly associated with blood donation were gender, being a member of an NGO, frequency of volunteering activities, fear of needles, and belief that they would acquire the disease during blood donation.

\section{CONCLUSION}

Most of the participants had good knowledge of blood donation, but their attitude and practice did not fall along the same lines. The study also highlighted that attitude towards donating blood is high among the participants who are associated with the NGOs or participate in voluntary activities. Voluntary work induces a 'sense of giving something to the society which appears to be facilitating factor and an effective measure to encourage blood donation among youth. 


\section{KEYWORDS}

Voluntary Blood Donation, practices, volunteerism, NGO, Students

\section{INTRODUCTION}

Voluntary blood donation started in 1942 in India, during the second world war when blood was vital in saving the lives of the injured ones. During that time, the blood donors were mainly government employees and the people from the Anglo-Indian fraternity who donated blood for a generous cause. [1] The number of voluntary donors declined after the war and the donors had to be paid for blood donation. [2] The World Health Organization (WHO) states that the safest blood donors are voluntary donors and the non-remunerated ones from low-risk populations. As per the Melbourne declaration, voluntary nonremunerated blood donation (VNRBD) has been globally declared to be the cornerstone of safe and secure blood. [3] In accordance with World Health Assembly resolution, which was adopted in 1975, WHO aims to obtain blood supplies through unpaid voluntary donors in all countries [3]. There is a huge gap between the demand and the supply in developing countries, especially in India due to the high prevalence of nutritional anemia. [4] It is estimated that India needs equivalent to 85 donations per 1000 eligible people, which was found to be equivalent to 31 donations per 1000 eligible people in 2018. Hence, there is a huge deficit that needs to be fulfilled with multisectoral efforts. [5] Blood scarcity is frequently encountered in healthcare settings and is attributable to an imbalance between the increasing demand for safe blood and blood products on the one hand and failure to organize regular blood supply due to misconceptions, perceived harms and risks, and lack of motivation among potential donors. [6]

Donated blood is very crucial in saving the lives of those who require large volumes of blood in an emergency. [7] Factors that promote blood donation include altruism/ humanitarian, personal or family credit, social pressure, replacement, and reward. Fear of needles, contracting an infection, and other adverse effects including medical problems are reasons which demotivate blood donors. [8, 9] Some studies have also shown poor blood donation practice among the students despite relatively good knowledge and favourable attitude toward voluntary blood donation. [10] The prevalence of voluntary blood donation is reported to be even lower among females. [1 1] Studies have revealed that there is a positive association among knowledge, attitude, and practice on blood donation, which suggests that positive attitude and practice can be improved by inculcating knowledge on blood donation among college students to recruit and donate blood regularly, which will help to achieve $100 \%$ of blood donation on a voluntary basis. [12, 13]

In India, the number of blood units collected through voluntary blood donation at the National AIDS Control Organization (NACO) supported blood bank was $84.3 \%$ in 2012. [14] Even today, recruiting volunteers for blood donation remains a major challenge. Almost every day around 12000 people die in India due to the lack of availability of donated blood and getting a safe blood supply on time remains a challenge. Over 40 districts in India does not have a single blood bank. [14, 15] Medical college students can serve as a readily available pool of voluntary blood donors for the attached medical college hospitals and help tide away some of the scarcity of blood and blood products. However, different studies involving medical students have expressed concern about the low level of awareness and unsatisfactory voluntary blood donation practices among them. Since student volunteers are potential sources of donated blood in society, it is essential to assess the factors which motivate and demotivate them in terms of blood donation., this study aimed to evaluate the knowledge, attitude, and practice of blood donation and to ascertain the factors which positively or negatively affects blood donation among the students at a university campus.

\section{MATERIALS AND METHODS}

\section{STUDY POPULATION}

A descriptive cross-sectional study was carried out in the university campus of Manipal from January 2018 to January 2019. A total of 354 students were interviewed who were selected using convenience sampling and met the inclusion criteria of being a current student at Manipal campus. Volunteers from other sister campuses of the university and those not consenting to the study were excluded. 


\section{MEASURES}

The study questionnaire comprises of two parts: part-A and part-B. The questionnaire was prepared by thorough literature review, then peer-reviewed, validated by two independent senior faculty members, pilot-tested, and administered to all the participants. The primary outcome was to assess the factors that influence the voluntary blood donation among the participants. Part A consisted 7 closeended questions on background information, such as gender; age; year of study; membership to any NGO/ Rotary/ Volunteer organization/ Volunteer Services Organization (VSO); the number of hours of voluntary services completed so far; type of family; frequency of involvement in voluntary work.

The part B of the questionnaire consisted of questions on knowledge, attitude, and practice of the participants towards blood donation.

\section{KNOWLEDGE TOWARDS BLOOD DONATION}

We used six questions to assess knowledge of the participants towards blood donation. These questions were about the "age at which a person can start to donate blood (16 years, 18 years, 21 years, Don't Know); minimum weight required to donate blood $(40 \mathrm{~kg}, 45 \mathrm{~kg}, 50 \mathrm{~kg}$, Don't Know); the volume of blood drawn out in each session $(450 \mathrm{ml}, 600 \mathrm{ml}, 650 \mathrm{ml}$, Don't Know); the minimum interval between two donations by a person ( 3 months, 6 months, 1 year, Don't Know); screening of donated blood prior to transfusion (Yes, No); aware that diseases can be acquired through transfusion of unscreened blood (Yes, No)." A score of one was assigned to each correct response and zero for incorrect response. All correct response results in a total knowledge score of 6 . The knowledge score was further classified as below average (if below 4), average (those who scored 4) and above average (above 4).

\section{ATIITUDE TOWARDS BLOOD DONATION}

In this study, we used eight questions to assess the attitude of the participants towards blood donation. These questions were, "Are you interested in donating blood (Yes, No); Why do people donate blood (Social Responsibility, Influence of friends, Religious purpose, For incentives/money, Screening for disease, Others); Do you have a fear of needles (Yes, No); Do you think the side effects of blood donation outweigh the benefits of doing so (Yes, No); Will you donate blood if an incentive is provided (Yes, No); Do you think one can acquire diseases while donating blood (Yes, No); Do you believe there will be any side effects to your body after donating blood (Yes, No); Which of the following do you think is the adverse effect of donating blood (Makes you weak, Anaemia, No adverse effects, Don't Know, Others)."

\section{PRACTICES, BARRIER TOWARDS BLOOD DONATION, AND A WAY TO IMPROVE}

This section consisted of seven questions to assess practices, barriers towards blood donation and a way to improve voluntary blood donation. The questions were "Have you donated blood before (Yes, No); Are you a frequent blood donor (Yes, No); Do you have any difficulty during the procedure (Yes, No); Will you recommend blood donation to others (Yes, No); If not donate blood before, Why you did not donated blood (Fear of needles, Lack of knowledge, Complicated procedure, No exposure to blood donation, Others)" The open-ended questions were used to understand ways to improve voluntary blood donation. These questions were, 'what will encourage you to donate blood?' and 'How do you think blood donation camps can be improved?'

\section{DATA COLLECTION AND STATISTICAL ANALYSIS}

The data on blood donation was collected by the interviewers (Interviewer Administered). The categorical variables were summarized using frequency \& percentage. The adjusted association was performed using logistic regression. The response to open-ended questions were coded (in vivo coding), categorised, and represented in the form of themes, and presented as frequency and percentages. A $p<0.05$ was considered significant. $R$ Console (4.0.1) was used for performing statistical analysis.

\section{ETHICAL CLEARANCE}

The study was approved by the Institutional Research Committee (IRC) \& Institutional Ethics Committee (IEC813/2017), of Manipal Academy of Higher Education. No personal identification was collected, and confidentiality was maintained throughout the course of the study.

\section{RESULTS}

A total of 354 responses were received and analysed. There were $38.41 \%(n=136)$ male and $61.58 \%(n=218)$ female respondents. Of 354 participants, majority ( $n=220,62.14 \%$ ) were aged between 20 and 25 years. A total of $38.98 \%$ $(n=138)$ participants had donated blood at least once. Out of 138 participants who donated blood, $55.8 \%(n=76)$ were males and $22.84 \%(n=62)$ were females and the majority $(n=102,43.36 \%)$ were in the age group of 20 to 25 years. 
Participants who were not members of any NGO (NonGovernment Organizations) ( $n=203,57.34 \%$ ), among them $45.81 \%(n=93)$ donated blood at least once. Even those volunteers who had worked once in the past six months, among them $65.22 \%(n=30)$ donated blood. The majority of the participants having knowledge scores of average, and above-average did not donate blood.

Among the volunteers who did not donate blood were those who said they are not afraid of needles $(n=146$, $56.15 \%)$, they did not require incentive $(n=80,56.34 \%)$, and they feel that diseases are acquired while blood transfusion $(n=136,64.15 \%)$. Among those who were interested in donating blood, most of them ( $n=198,59.28 \%$ ) did not donate blood. The main reasons for not donating blood among non-donors were that it makes them weak $(n=22)$ and that they did not know they should donate $(n=40)$. The majority $(n=210,59.32 \%)$ of the respondents selected other reasons as an option for not donating blood. The other reasons which non-donors $(n=126)$ quoted were low haemoglobin $(n=60)$, underweight $(n=35)$, personal choice $(n=22)$, and medical conditions like diabetes, low BP, on medications, etc. $(n=9)$ for not donating blood. Out of 354 participants, 115 (32.48\%) responded to the open-ended question on 'what will encourage you to donate blood?'. Most of the responses were, social responsibility $(n=54$, $46.95 \%)$, feeling of contentment ( $n=50,43.47)$ and proper education ( $n=11,3.10 \%)$. Two hundred and eight (58.57\%) participants responded to the open-ended question on 'How do you think blood donation camps can be improved?'. Major themes that emerged for this are publicity (pamphlets, posters, social media) ( $n=49,23.56 \%)$, education and awareness ( $n=76,36.53 \%)$, incentive (attendance, food, certificates, free blood test) $(n=33,15.87 \%)$, hygiene and sanitation at the collection point $(n=20,9.62 \%)$ and more comforting atmosphere $(n=30,14.42 \%)$. Descriptive for other variables are presented in Table I.

TABLE I: DESCRIPTIVE OF VARIABLES UTILIZED IN THE STUDY FOR BLOOD DONATION ( $\mathrm{N=354)}$

\begin{tabular}{|c|c|c|c|}
\hline \multirow[t]{2}{*}{ VARIABLES } & \multirow{2}{*}{$\begin{array}{l}\text { NUMBER } \\
\text { (PERCENTAGE) } \\
\text { N (\%) }\end{array}$} & \multicolumn{2}{|c|}{ BLOOD DONATION } \\
\hline & & YES, N (\%) & NO, N (\%) \\
\hline \multicolumn{4}{|l|}{ Gender } \\
\hline Male & $136(38.42)$ & $76(55.8)$ & $60(44.12)$ \\
\hline Female & $218(61.58)$ & $62(28.44)$ & $156(71.56)$ \\
\hline \multicolumn{4}{|l|}{ Age } \\
\hline Below 20 & $118(33.33)$ & $26(22.03)$ & $92(77.97)$ \\
\hline $20-25$ & $220(62.14)$ & $102(46.36)$ & $118(53.64)$ \\
\hline $25-30$ & $12(3.39)$ & $6(50)$ & $6(50)$ \\
\hline Above 30 & $4(1.13)$ & $4(100)$ & 0 \\
\hline \multicolumn{4}{|l|}{ Year of Study } \\
\hline 1st year & $70(19.77)$ & $27(38.57)$ & $43(61.43)$ \\
\hline 2nd year & $148(41.81)$ & $44(29.73)$ & $104(70.27)$ \\
\hline $3^{\text {rd }}$ year & $110(31.07)$ & $49(44.55)$ & $61(55.45)$ \\
\hline $4^{\text {th }}$ year & $16(4.52)$ & $8(50)$ & $8(50)$ \\
\hline $5^{\text {th }}$ year & $2(0.56)$ & $2(100)$ & $0(0)$ \\
\hline Intern & $8(2.26)$ & $8(100)$ & $0(0)$ \\
\hline \multicolumn{4}{|c|}{ Member of NGO } \\
\hline Yes & $151(42.65)$ & $45(29.8)$ & $106(70.2)$ \\
\hline No & $203(57.34)$ & $93(45.81)$ & $110(54.19)$ \\
\hline \multicolumn{4}{|c|}{ Volunteering Service Hours } \\
\hline Hour $<5$ & $210(59.32)$ & 79 (37.62) & $131(62.38)$ \\
\hline $5-10$ & $48(13.56)$ & $23(47.92)$ & $25(52.08)$ \\
\hline $10-20$ & $36(10.17)$ & 14 (38.89) & $22(61.11)$ \\
\hline $20<$ hour & $60(16.95)$ & $22(36.67)$ & $38(63.33)$ \\
\hline
\end{tabular}




\begin{tabular}{|c|c|c|c|}
\hline Type of Family & & & \\
\hline Nuclear & $294(83.05)$ & $114(38.78)$ & $180(61.22)$ \\
\hline Joint & $60(16.95)$ & $24(40)$ & $36(60)$ \\
\hline \multicolumn{4}{|l|}{ Volunteering Work } \\
\hline Once in week & $61(17.23)$ & $19(31.15)$ & $42(68.85)$ \\
\hline Once in month & $74(20.90)$ & $26(35.14)$ & $48(64.86)$ \\
\hline Once in six months & $46(12.99)$ & $30(65.22)$ & $16(34.78)$ \\
\hline Once in Year & $26(7.34)$ & $10(38.46)$ & $16(61.54)$ \\
\hline Rarely & $125(35.31)$ & $47(37.60)$ & $\begin{array}{ll}78 & (62.40)\end{array}$ \\
\hline Never & $22(6.21)$ & $6(27.27)$ & $16(72.73)$ \\
\hline \multicolumn{4}{|l|}{ Knowledge Score } \\
\hline Below Average & $81(22.88)$ & $27(33.33)$ & $54(66.67)$ \\
\hline Average & $107(30.22)$ & $37(34.58)$ & $70(65.42)$ \\
\hline Above Average & $166(46.89)$ & $74(44.58)$ & $92(55.42)$ \\
\hline \multicolumn{4}{|c|}{ Why do people donate blood } \\
\hline Social responsibility & $326(92.10)$ & $130(39.88)$ & $196(60.12)$ \\
\hline Influence of friends & $04(1.13)$ & $01(25)$ & $03(75)$ \\
\hline Religious purpose & $02(0.56)$ & $02(100)$ & $00(0)$ \\
\hline For incentives/money & $06(1.69)$ & 02 (33.33) & $04(66.67)$ \\
\hline Screening for disease & $04(1.13)$ & $01(25)$ & $03(75)$ \\
\hline Others & 12 (3.39) & $02(16.67)$ & $10(83.33)$ \\
\hline \multicolumn{4}{|l|}{ Fear of Needle } \\
\hline Yes & $94(26.55)$ & $24(25.53)$ & $70(74.47)$ \\
\hline No & $260(73.45)$ & $114(43.85)$ & $146(56.15)$ \\
\hline \multicolumn{4}{|c|}{$\begin{array}{l}\text { Side effects of blood donation } \\
\text { outweigh the benefits of doing so }\end{array}$} \\
\hline Yes & $89(25.14)$ & $39(43.82)$ & $50(56.18)$ \\
\hline No & $265(74.86)$ & $99(37.36)$ & $166(62.64)$ \\
\hline \multicolumn{4}{|c|}{$\begin{array}{l}\text { Donate blood if incentive is } \\
\text { provided }\end{array}$} \\
\hline Yes & $285(80.51)$ & $119(41.75)$ & $166(58.25)$ \\
\hline No & $69(19.49)$ & $19(27.54)$ & $50(72.46)$ \\
\hline \multicolumn{4}{|c|}{$\begin{array}{l}\text { Acquire disease while blood } \\
\text { donation }\end{array}$} \\
\hline Yes & $212(59.89)$ & $76(35.85)$ & $136(64.15)$ \\
\hline No & $142(40.11$ & $62(43.66)$ & $80(56.34)$ \\
\hline \multicolumn{4}{|c|}{ Adverse effect of blood donation } \\
\hline Makes you weak & $138(38.98)$ & $45(32.61)$ & $93(67.39)$ \\
\hline Anemia & $30(8.47)$ & $12(40.00)$ & $18(60.00)$ \\
\hline No adverse effect & $125(35.31)$ & $55(44.00)$ & $70(56.00)$ \\
\hline Don't Know & $46(12.99)$ & $25(54.35)$ & $21(45.65)$ \\
\hline Others & $15(4.24)$ & $1(6.67)$ & 14 (93.33) \\
\hline \multicolumn{4}{|c|}{ Are you a frequent blood donor } \\
\hline Yes & $68(19.21)$ & $61(89.71)$ & $7(10.29)$ \\
\hline No & $286(80.79)$ & $77(26.92)$ & $209(73.08)$ \\
\hline \multicolumn{4}{|c|}{ Difficulty during procedure } \\
\hline Yes & $65(18.36)$ & $16(24.62)$ & $49(75.38)$ \\
\hline No & $289(81.64)$ & $122(42.21)$ & $167(57.79)$ \\
\hline
\end{tabular}




\begin{tabular}{|l|l|l|l|}
\hline Reason for never donating blood & & & \\
\hline Makes you weak & $37(10.45)$ & $15(40.54)$ & $22(59.46)$ \\
\hline No adverse effect & $55(15.54)$ & $27(49.09)$ & $28(50.91)$ \\
\hline Don't Know & $52(14.69)$ & $12(23.08)$ & $40(76.92)$ \\
\hline Others & $210(59.32)$ & $84(40.00)$ & $126(60.00)$ \\
\hline $\begin{array}{l}\text { Will you recommend blood } \\
\text { donation }\end{array}$ & & & \\
\hline Yes & $348(98.31)$ & $138(39.66)$ & $210(60.34)$ \\
\hline No & $6(1.69)$ & $0(0)$ & $6(100)$ \\
\hline Encourage blood donation & & & \\
\hline Attendance & $58(16.38)$ & $32(55.17)$ & $26(44.83)$ \\
\hline Half day & $62(17.51)$ & $18(29.03)$ & $44(70.97)$ \\
\hline Incentive & $72(20.34)$ & $22(30.56)$ & $50(69.44)$ \\
\hline Gift & $14(3.95)$ & $8(57.14)$ & $6(42.86)$ \\
\hline Money & $31(8.76)$ & $13(41.94)$ & $18(58.06)$ \\
\hline Other & $117(33.05)$ & $45(38.46)$ & $72(61.54)$ \\
\hline Side effect after blood donation & & & \\
\hline Yes & $260(73.45)$ & $108(41.54)$ & $152(58.46)$ \\
\hline No & $94(26.55$ & $30(31.91)$ & $64(68.09)$ \\
\hline
\end{tabular}

The study revealed that blood donation was associated with various factors after adjusting for confounders: females had 3.3 times odds of donating blood compared to males (OR (95\% Cl): 3.396 (2.060-5.684); $p=0.00)$. Those who were not a member of any NGO had $53 \%$ lower odds of donating blood compared to those who are a member (OR $(95 \% \mathrm{Cl})$ : 0.47 (0.251-0.882); $p=0.01)$. Those who volunteer once in 6 months had $68 \%$ lower odds of donating blood compared to those who volunteer once in a week (OR $(95 \% \mathrm{Cl}): 0.32$ (0.1 18-0.887); $p=0.02$ ). Those who were afraid of needles had $46 \%$ lower odds of donating blood compared to those who do not have fear (OR (95\% Cl): 0.54(0.298-0.961); $\mathrm{p}=0.03$ ). and those who feel that they acquire disease while blood donation had $44 \%$ lower odds of donating blood compared to those who feel otherwise (OR $(95 \% \mathrm{Cl})$ : $0.56(0.331-0.942) ; p=0.03)$.

TABLE II: ADJUSTED ODDS RATIO FOR PREDICTOR VARIABLES FOR BLOOD DONATION.

\begin{tabular}{|l|l|l|}
\hline VARIABLE & ODDS RATIO $(95 \% \mathrm{CI})$ & P VALUE \\
\hline Gender & & \\
\hline Male & 1 & \\
\hline Female & $3.39(2.06-5.68)$ & $0.0000^{*}$ \\
\hline Member of NGO & & \\
\hline Yes & 1 & \\
\hline No & $0.47(0.25-0.88)$ & $0.0199^{*}$ \\
\hline Volunteer services hours & & \\
\hline Less than 5 h & 1 & \\
\hline $5-10$ & $0.87(0.39-1.94)$ & 0.7500 \\
\hline $10-20$ & $0.79(0.30-2.13)$ & 0.6501 \\
\hline Above 20 h & $0.66(0.26-1.61)$ & 0.3656 \\
\hline Frequency of voluntary work & & \\
\hline
\end{tabular}




\begin{tabular}{|l|l|l|}
\hline Once in Week & 1 & \\
\hline Once in Month & $0.65(0.27-1.50)$ & 0.3262 \\
\hline Once in 6 Month & $0.32(0.11-0.88)$ & $0.0299^{*}$ \\
\hline Once in Year & $1.15(0.36-3.69)$ & 0.8084 \\
\hline Rarely & $0.96(0.39-2.35)$ & 0.9312 \\
\hline Never & $2.63(0.70-10.69)$ & 0.1607 \\
\hline Knowledge score & & \\
\hline Below Average & 1 & \\
\hline Average & $0.77(0.48-1.22)$ & 0.2796 \\
\hline Above Average & $0.67(0.42-1.06)$ & 0.0937 \\
\hline Fear of needle & & \\
\hline Yes & 1 & \\
\hline No & $0.54(0.29-0.96)$ & $0.0392^{*}$ \\
\hline Incentive for blood donation & & \\
\hline Yes & 1 & \\
\hline No & $1.87(0.95-3.80)$ & \\
\hline $\begin{array}{l}\text { Acquired disease during blood } \\
\text { donation }\end{array}$ & & 0.0740 \\
\hline Yes & 1 & \\
\hline No & $0.56(0.33-0.94)$ & \\
\hline Interested in blood donation & & \\
\hline Yes & 1 & \\
\hline No & & \\
\hline
\end{tabular}

Cl: Confidence Interval, Significant values*

\section{DISCUSSION}

Escalating demand for safe blood and its availability in society can be assured only through enhancing voluntary blood donation. The role of volunteers is crucial to meet the demand for safe blood as they have a better understanding of healthcare requirements. The findings of our study are very similar to a study in Iran where $38 \%$ of respondents had ever donated blood which is $38.98 \%$ in our study. [16] There is also a significant increase in blood donation compared to the earlier study in India where they had only $10 \%$ of voluntary donors. [17] However, this proportion is relatively low when compared with studies among students from Nepal (43\%), USA (56\%) for blood donation. [18, 19] Our study revealed that males were more active in donating blood. There is evidence that women donate less blood mostly due to physiological problems and low haemoglobin count. [20] Several factors were found to be predictors of blood donation. We found a significant association between being an NGO member

and donating blood. There are studies that support our findings that being an NGO member provides a sense of social responsibility and community welfare. [21, 22] We found that participants with nuclear families were less likely to donate blood which is in contrast with the study conducted in North India, which concluded that individuals from nuclear families were more likely to donate blood. [17] Even those participants who responded that it is a social responsibility to donate blood, have no fear of needles, and do not anticipate a difficulty during the procedure and agreed that there are no side effects of 
blood donation, did not go for blood donation. This might be because of various misbeliefs or social constraints in society towards blood donation. The most cited reason to donate blood was a sense of social responsibility. [23] Most of the studies have evidenced that fear of needles and associated side effects like weakness, the transmission of diseases, etc. are the major reasons for not donating blood. [7] Any associated side effects from blood donation should be properly documented for any medico-legal case and even for research purposes. [24] In the present study, weakness, lack of awareness, low haemoglobin levels, underweight, personal choice, and medical conditions like diabetes, hypotension, under medications were mainly the stated reasons for not donating blood. This could also be attributed to poor knowledge about blood donation in general. Most of the participants who were not donating blood had average knowledge which is indicative of their negative behaviour towards blood donation. Majority of the participants responded that through education and awareness blood donation among students can be improved in the campus.

This study had few limitations too. The sample size utilized was not enough to generalize the findings. The crosssectional nature of the study which is used may also hinder the cause-and-effect relationship. Future studies using a very large sample size are recommended for generalizing the findings.

\section{CONCLUSION}

Majority of the participants had good knowledge of blood donation, but their attitude and practice did not fall along the same lines. The study also highlighted that attitude towards donating blood is high among the participants who are associated with the NGOs or participate in voluntary activities. Voluntary work induces a 'sense of giving something to the society' which appears to be facilitating factor and an effective measure to encourage blood donation among youth. Incentivisation for blood donation proves to be another motivating factor. Innovative methods like health-related incentives such as blood credit, health screening. and economic incentives like a ticket to events, discount coupons etc. should be planned to encourage students for blood donation.

Age and gender are importantidentifier for those unwilling to donate blood for a noble cause. Educational programs, digital communication material on blood donation and way to mitigate misconceptions towards blood donation and blood transfusion should be prepared for the women in the respective age groups and run through the internet and social media regularly to curb the myths associated with blood donation and to motivate them to become a potential blood donor. Barriers to blood donation among women should be found out through in-depth studies. Government Health Officials should work towards this so that people do not have any misconceptions associated with the procedure. Education Institutions can play an active role in facilitating the youth to become safe blood donors and meet the blood requirement of any country. They should be encouraged to take lead in creating awareness programs, work in collaboration with medical institutions to create a curriculum on the topic of blood donation and impart learnings and motivate the student community to donate blood.

\section{DECLARATIONS}

\section{Authors Contribution}

$A C, P R$, and LK were involved in study concept, design, and data collection. AK carried out cleaning of data and statistical analysis. BT and AC wrote the manuscript. AG and PM did critical review of the paper. All authors have read and approved the manuscript.

\section{Acknowledgements}

We would like to thank our participants for their time and participation.

\section{Conflicts of Interest}

Authors have no competing interests.

\section{References}

1. Marwaha, N.J.A.j.o.t.s., Voluntary blood donation in India: Achievements, expectations and challenges. 2015.9(Suppl 1): p. S1.

2. Grassineau, D., et al., Improving minority blood donation: anthropologic approach in a migrant community. 2007. 47 (3): p. 402-409.

3. Organization, W.H., Action framework to advance universal access to safe, effective and quality-assured blood products 2020-2023.2020.

4. Rai, R.K., et al., The burden of iron-deficiency anaemia among women in India: how have iron and folic acid interventions fared? 2018.7(1): p. 18-23. 
5. Mammen, J.J. and E.S.J.T.L.H. Asirvatham, The demand and supply of blood in India. 2020. 7 (2): p. e94.

6. Manikandan, S., R. Srikumar, and P.J.I.J.S.R.P. Ruvanthika, A study on knowledge, attitude and practice on blood donation among health professional students in Chennai, Tamil Nadu, South India. 2013.3(3): p. 1-4.

7. Nwogoh, B., U. Aigberadion, and A.I.J.J.o.b.t. Nwannadi, Knowledge, attitude, and practice of voluntary blood donation among healthcare workers at the University of Benin Teaching Hospital, Benin City, Nigeria.2013.2013.

8. Marantidou, O., et al., Factors that motivate and hinder blood donation in Greece. 2007.17(6): p. 443 450 .

9. Martín Santana, J.D. and A.J.R.e.d.I.d.M.E. Beerli Palacio, El comportamiento del donante de sangre desde la perspectiva del marketing social: factores determinantes de la predisposición a donar. 2008.

10. Mishra, S.K., et al., Study of knowledge and attitude among college-going students toward voluntary blood donation from north India. 2016. 7: p. 19.

11. Chauhan, R., et al., A study to assess the knowledge, attitude, and practices about blood donation among medical students of a medical college in North India. $2018.7(4):$ p. 693.

12. Kowsalya, $\vee$., et al., A study on knowledge, attitude and practice regarding voluntary blood donation among medical students in Puducherry, India. 2013. 16(9): p. 439-442.

13. Raghuwanshi, B., et al., Voluntary blood donation among students-a cross-sectional study on knowledge and practice vs. attitude. 2016.10(10): p. EC18.

14. Kumar, A., et al., Analysis of reasons for discarding blood and blood components in a blood bank of tertiary care hospital in central India: A prospective study. 2014. 4(1).

15. Chhabra, R.J.E. and P. Weekly, National AIDS control programme: a critique. 2007: p. 103-108.

16. Nwabueze, S., et al., Perception of blood donation among medical and pharmaceutical science students of Nnamdi Azikiwe University, Awka. 2014. 2014.
17. Singh, B., et al., Knowledge, attitudes and sociodemographic factors differentiating blood donors from non-donors in an urban slum of Delhi. 2002. 27(3): p. 118.

18. Allerson, J.T., Assessment of selected university students' knowledge of blood donation and the relationship with intent to donate blood. 2012: Minnesota State University, Mankato.

19. Mamatya, A., R. Prajapati, and R.J.N.M.C.J. Yadav, Knowledge and practice of blood donation: a comparison between medical and non-medical Nepalese students. 2012.14(4): p. 283-6.

20. Bahadur, S., M. Pujani, and M.J.A.j.o.t.s. Jain, Donor deferral due to anemia: A tertiary care center-based study. $2011.5(1)$ : p. 53.

21. Alabdullatif, M. and S.J.V.s. Ramirez-Arcos, Biofilmassociated accumulation-associated protein (Aap): A contributing factor to the predominant growth of Staphylococcus epidermidis in platelet concentrates. 2019.114(1): p. 28-37.

22. Alessandrini, M.J.T.m.r., Community volunteerism and blood donation: altruism as a lifestyle choice. 2007. 21 (4): p. 307-316.

23. Uma, S., et al., The knowledge, attitude and practice towards blood donation among voluntary blood donors in Chennai, India. 2013.7(6): p. 1043.

24. Khan, M.A., et al., Documentation compliance of inpatient files: A cross sectional study from an east India state. 2020. 8(4): p. 994-997. 